\title{
Research on the Whole Beasts God Images of Shanhai Jing ShuYan $Y_{i}{ }^{1,} a^{*}$ Jing Wang ${ }^{1, b}$ \\ ${ }^{1}$ College of Humanities \&Sciences of Northeast Normal University, Chang chun, Ji lin, China, 130117 \\ a yishuyan2013@126.com, bangjingart@163.com
}

Keywords: Shanhai Jing; God; Image; Myth

\begin{abstract}
Shanhai Jing is an important ancient books of the pre-Qin Period, Where the whole beasts God images not only provide important literature material for us to understand the early religious thought, also provide a powerful image picture. Based on the relevant text analysis, it can be found: the God's identity mostly are mountain god and the mammals which involved are from different areas, such as oxen and horses birds dragons snakes.[1] This is the embodiment of the primitive totem worship psychology, the primitive people have different feelings in different animals. After all, through the related God image's text content in Shanhai Jing, we not only can have deep contact with the image of God, but also can find the sacrificial rites, aesthetics, religion etc. The sacrifice ritual and religious thought chronicled by Shanhai Jing is not only have a summary of the previous generation, but also have an important impact on future generations[2].
\end{abstract}

\section{Introduction}

As an important ancient books of pre-Qin period, Shanhai Jing has recorded mythology. It is not only considered as the earliest but also the most abundant ancient book, which handed down from ancient times so far in China. Not only the God's number of which is rich, but also the God's image is bizarre, which have great research value. Through the classification of different God images of Shanhai Ching, it can reveal the deep ideological and cultural connotations hidden behind, which has great advantage to grasp the ancient human spirit worship psychological development[3][4].

Mr. Hong $\mathrm{Wu}$ believed that the Art and literature created by people (including oral literature) should be parallel to each other in a particular period of time and culture, all reflect the special angles and ideas of human observation, understanding and performance the world[5]. The God image of Shanhai Jing is the embodiment of this special angle and specific ideas[6]. By studying the whole beast God images, this article's aim is to find out the different mythological concept. The details are as follows.

\section{Analysis of Shanhai Jing's whole beast God image}

The whole beast God is the God completely composed by the combination of animal organs. By statistics of the distribution of its occurrences, the animal species involved, the geographical distribution of meticulous statistics, we find some role of the full beast God image existing.

The full beast God image appeared location. In Shanhai Jing section, the whole beast image God appears rare, they are more focused on Mountain Classic section, especially abundant in Nanshan Jing and Zhongshan Jing.

In Nanshan Jing, these god appears in two mountain groups, they are the first mountain of the Nan Shan Jing and the the second part of Nanshan Jing in turns. They are mountain gods. One god is in charge of the first investigation route of the southern regions, stretching from the Zhaoyao Mountain to the Jiwei Mountain, includes 10 mountains, and covers an area of $2950 \mathrm{Li}$. The second god is responsible for investigation route of the southern regions, streching from the Juwu Mountain to Xiwu Mountain, includes 17 mountains, and covers an area of $7200 \mathrm{Li}$.

In Zhongshan Jing, these kinds of god appear in mountains of the ninth and the twelfth part of 
Zhongshan jing in turns, their responsibilities and the identities are the same as above mentioned. The first god is in charge of the Min Mountain Chain is the ninth investigation route of the central regions, from Nvji Mountain to Jiachao Mountain, including 16 mountains and $3500 \mathrm{Li}$ altogether. The second god's domained the Dongting Mountain Chain is the twelfth investigation route of the central regions, from the Pianyu Mountain to the Rongyu Mountain, including 15 mountains and $2800 \mathrm{Li}$.

In addition, the all-beast god also occasionally appear in the Beishan Jing and Xishan Jing. In the third of Beishan Jing, they are the god which charges the area of the third investigation route of the northern regions includes 46 mountains and stretches $12350 \mathrm{Li}$, from the Gui Mountain to the Wufeng Mountain. While in the third of Xishan Jing, the whole beast God's responsibility is slightly different from the others, he is a celestial[7].

God image involves the beast. The image of the full beast god in Shanhai Jing's text are mainly based on two parts that is the body and the head, sometimes involving the foot, tail and other body organs.In genera, the image of god usually is combinated by two or three different beast organ. To be clear, the beast is a broad concept, it not only points to the cattle, horse, sheep, also includes birds, snakes, dragon, etc[8]. The texts as mentioned are as follows:

1) The image of the god is composed of the bird body and the head of dragon. (Nanshan Jing)

2) The image of the god is composed of the dragon body and the head of bird. (the second part of Nanshan Jing)

3) The ten mountains spirits within these mountains are pig body but have eight feet and snake tail. (the third part of Beishan Jing)

4) The soirit of the Huai Mountain resembles the cattle, but having eight feet, two heads, a horse tail, and a voice of Bohuang. (the third part of Xishan Jing)

5) The image of the god is composed of the horse body and the head of dragon. (the ninth part of Zhongshan Jing)

6) The image of the god is composed of bird body and head of dragon. (the twelfth part of Zhongshan Jing).

From the above exemplified text, we found that: The images of the full beast god were involved in the bird, dragon, snake, horse, cattle, pig and other different animals.

Table 1 The mammals image appears location in Shanhai Jing

\begin{tabular}{ccc}
\hline Animal names & Number of occurrences & Location of scripture \\
\hline Dragon & 4 & Nanshan Jing, Zhongshan Jing \\
\hline Bird & 3 & Nanshan Jing, Zhongshan Jing \\
\hline Horse & 2 & Xishan Jing, Zhongshan Jing \\
\hline Pig & 1 & Beishan Jing \\
\hline Snake & 1 & Beishan Jing \\
\hline Cattle & 1 & Xishan Jing \\
\hline
\end{tabular}

As seen in Table 1, the times that the animals appeared were different: the dragon is four times, the bird is three times, the horse is two times, while cattle, pig and snake is only each one time. In the Nanshan Jing section, the all-beast God image respectively involved two animals, that is the bird and the dragon, and the difference between the two kinds god image is the body and the head's sequence exchanged. The common point of the god images appeared in the Zhongshan Jing position is that they all have the dragon head, the difference is one has the horse body and the other has the bird body. After compared the god images in Nanshan Jing with the god images of Zhongshan Jing, we find that both of them have bird body and dragon head. [9]Their images are as shown in Fig 1[10] and Fig 2[11]. 


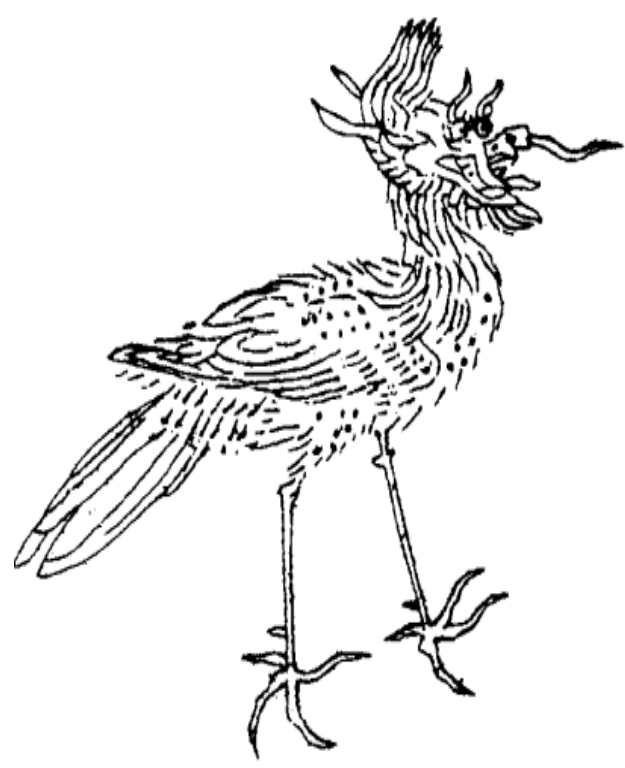

Figure. 1 The god images in Nanshan Jing

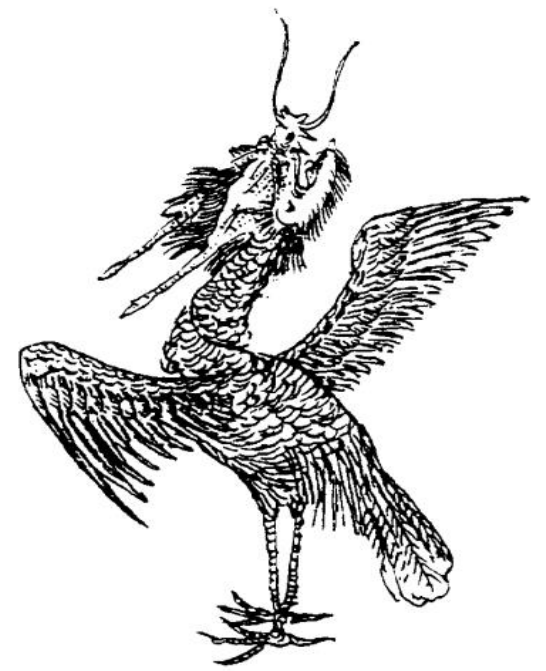

Figure. 2 The god images in Zhanshan Jing

Although the images of full beast God appears only 6 times in Shanhai Jing, whose frequency is much smaller than the other types of Gods, it has an important historical value. From these scattered text content, we can find that the importance and the degree of dependence of these kinds of animals to the primitive man, which is helpful to probe the pioneers of the original worship consciousness in the long historical process of evolution.

\section{Deciphering the password of the image of all-beast Gods in Shanhai Jing}

First, the text of Shanhai Jing has provided factual evidence for people to study the evolution of worship to trajectory psychological aspects of the primitive in ancient times.

Through a variety of image of the image of all-beast Gods, we could confirm the "totem" theory which was put forward by lewis Henry Morgan, who was the 19th century American ethnologist. "Totem" is a word borrowed from North American Indian language, its literal translation is relatives, or it's relatives. The essence of totem is the ancestor god and protector who were worshiped by the whole clan[12].

Although the images of the whole beast God we studied mostly belonged to mountain god in 
nature, but it can still be classified as protection of God category. In another sense, they were the original inhabitants of life to a particular region, who played the role of God to protect. The whole beast God images has close relationship with the daily life materials needed and the safety consciousness of the original ancestors. In view of the above reasons, the original settlers created them. Therefore they were responsible to protect the lives of the whole clan. In a nutshell, they are the product of primitive ancestors totem worship.

In addition, through the brief record of the sacrifice ritual texts, you can see the sincerest hearts of the original settlers. When saluting to the gods of the mountains, they not only offered the carefully selected meat such as chicken, dog, cattle, sheep and other animals, and also offered the rice as meal, the wine, jade and other items. In this way, the primitive man pleasure the mountain god. After dedicated everything to the god through the store buried approach, the original settlers hoped to obtaining protection, achieving good harvest.

Second, the mentioned text also convinced the primitive ancestors different worship degree to dragons, birds and other animals.

As everyone knows, in the Neolithic period, the humans have begun to raise horses, cattle, sheep and other livestock, and make them become as a necessity helper of human life.Therefore, the human have a deep feeling of gratitude to the cattle and horses. Under the control of this kind of emotion, human began to join the cattle body into the God image in order to express their worship. The God image of case 4 and case 5 mentioned above just reflected the primitive sincere friendship to cattle, horses[13].

In ancient times, the survival of the human environment was very harsh, the primitive man's life safety was seriously threatened frequently. The flood, the beast had brought great distress to primitive life. In this case, the birds which can freely flying in the sky become the object of human worship. The images of God in 1 case and 2 cases have reflected the primitive people flying dreams just like birds. From the jades which were unearthed from the late Neolithic Liangzhu Culture 5300-4200 years before, we can see the primitive's birds worship psychology. The jade birds and the Jade-congs are good evidence which were founded under the Fan mountain cemetery[14].

Different from the mentioned animals such as the dragon, the cattle, the horse, and the bird, etc. the dragon is a complex type animals by human's fantasy. It's main body is composed by the snake, and the other body organs are composed by the horses, the deer, the dog, the fish in different areas. In China, the dragon worship has a long history. According to the archaeological discovery, we can find that the new stone age was an important period for the development of dragon worship.The dragon pottery excavated in Chahai ancient cultural relic eight thousand years ago were the earliest evident of dragon worship so far. The 2 case and the 5 case's image of God also revealed that the primitive worship of the dragon, which is a combination of dragon worship form. This is a comprehensive reflection of the original ancestors different emotions,such as fear, friendly and dream, etc.

\section{Conclusion}

The whole beast God image is a smaller branch of Shanhai Jing's various God's image. Its outer Image is the direct reflection of primitives' weak phase, when the human completely surrendered to nature. The God's image can reflect the state of mind with the fear of nature, the worship of nature and the desire to conquer the natural,which is the direct evidence of totem worship. It also has provided an important first hand data for the study of the origin myth.

\section{References}

[1] [Jin]P. Guo: Notes.ShanHai Jing(Photocopy this Wenyuange Sikuquanshu, Shanghai Ancient Books Publishing House, Chinese 1999). 
[2] Y.D. Wen: Myths and Poems(East China Normal University Press, Chinese 1997). p. 199.

[3] Y.S. Fu: Ancient ritual culture(Higher Education Press, Chinese 2005). p. 168.

[4] K. Yuan: Shanhai Jing School Note(Shanghai: Shanghai Ancient Books Publishing House, Chinese 1980). p. 68.

[5] H.Wu: Bird Image IN EGL Art.(SDX Joint Publishing Company, Chinese 2005). p. 28.

[6] Z.D. Liu: The Lost bible--Shan Hai Jing and the ancient China world(Commercial Press, Chinese 2010).

[7] X.H. Liu: Chinese civilization Yi October calendar(Yunnan People's Publishing House, Chinese 1986). p. 33.

[8] X.S. Ye: Theoretical Studies in Literature and Art. Vol. 181 (2012) No.2, p.24.

[9] B.H. Li: Gansu Social Sciences, Vol. 197 (2012) No.2, p.7.

[10] C.Y. Ma: The Ancient Map of Shanhai Jing( Shandong Pictorial Publishing House, Chinese 2001).p. 25.

[11] C.Y. Ma: The Ancient Map of Shanhai Jing( Shandong Pictorial Publishing House, Chinese 2001).p. 405.

[12] S.Y. Yi, Y.S. Fu: Research of Chinese Literature. Vol. 103 (2011) No.4, p.28.

[13] Y.F. Chen: Journal of Minorities Teachers College of Qinghai Teachers University. Vol.38 (2011) No.2, p.13.

[14] H.W. Liu: Archaeology and Cultural Relics. Vol.165 (2008) No.1, p.29. 